\title{
IDENTIFIKASI JENIS POHON PENGHASIL BUAH KONSUMSI DI KAWASAN HUTAN TEMBAWANG DUSUN SUAK DESA MANIS RAYA KECAMATAN SEPAUK KABUPATEN SINTANG
}

\author{
(Identification Of Consumtion Fruits Trees at Tembawang Sub Village Suak, Manis Raya \\ Village Sepauk District Sintang Regency)
}

\author{
Oktavianti Paulina, Togar Fernando M, Slamet Rifanjani \\ Fakultas Kehutanan Universitas Tanjungpura Pontianak. Jalan Daya Nasional Pontianak 78124 \\ Email: oktaviantipaulina57@gmail.com
}

\begin{abstract}
Identification is determining the identity of a species, which in this case determines the correct name and place in the classification. Tembawang Forest is a form of land management carried out by Dayak tribes in West Kalimantan. Tembawang Suak has various fruit trees species which are usually used by people around the forest. This research was conducted in Tembawang Forest at Suak Subvillage, Manis Raya Village, Sepauk District, Sintang Regency, West Kalimantan. The purpose of this study is to identify and describe the morphological characteristics of fruits trees species in the Tembawang Forest Area. The method in this research is an exploration method which is carried out by taking data with making pathways to facilitate roaming at the research location to find the fruit trees species and then taking a sample of the herbarium. Data analysis by describing morphological characteristics (generative and vegetative) in detail. Based on the research results, there are 30 species of consumption fruit trees that are classified into 16 genera and 13 families, and 5 species of which are endemic to Kalimantan, namely Manginfera pajang Kosterm (Asam Mawang), Shorea stenoptera Burck. (Tengkawang Tungkul), Durio kutejensis (Hassk.) Becc. (Pekawai), Sarcotheca macrophylla Blume (Rembai/Belimbing Hutan), and Baccaurea angulata Merr (Menit/Belimbing Darah).
\end{abstract}

Keyword: Tree Identification, Fruit Producers, Tembawang Forest

PENDAHULUAN

Identifikasi tumbuhan sangat penting untuk mengenali tumbuhan itu sendiri seperti yang telah disepakati ditingkat dunia agar memahami bahwa yang dimaksudkan adalah tumbuhan yang sama. Identifikasi tumbuhan berarti mengungkapkan atau menetapkan identitas suatu tumbuhan, yang dalam hal ini tidak lain dari pada menentukan namanya yang benar dan tempatnya yang tepat dalam sistem klasifikasi (Wahyuni 2017 ).
Pohon penghasil buah-buahan hutan menjadi lebih penting sebagai sumber pangan. Pohon penghasil buah-buahan yang dapat dikonsumsi diantaranya adalah durian, manggis, lengkeng, cempedak, serta yang harus diolah terlebih dahulu seperti tengkawang (Hani 2009). Hutan Tembawang adalah suatu area bekas rumah panjang yang di tumbuhi oleh berbagai jenis tanaman penghasil buah-buahan seperti durian, rambutan, langsat, cempedak dan tengkawang (Darusman 2001). Hutan 
Tembawang merupakan bagian dari pola sistem hutan kerakyatan yang ada pada masyarakat disekitar hutan, pada umumnya Hutan Tembawang diusahakan oleh masyarakat sebagai usaha kebun buah-buahan dan kayukayuan, dari pengelolaan masyarakat memperoleh produk yang dapat dihasilkan seperti buah-buahan (Roslinda 2008).

Hutan Tembawang merupakan habitat bagi jenis-jenis tumbuhan yang dimanfaatkan oleh masyarakat, terutama pohon penghasil buah yang dapat dikonsumsi. Seiring perkembangan zaman, maraknya kegiatan illegal logging, pembukaan wilayah hutan, industri kehutanan, dan perkebunan secara besar-besaran, dikhawatirkan dapat mengurangi keberadaan jenis-jenis pohon hutan termasuk jenis-jenis pohon penghasil buah konsumsi. Keberadaan jenis pohon buah, terutama di Hutan Tembawang Dusun Suak perlu dilakukan langkah konservasi.

Tembawang Dusun Suak memiliki berbagai jenis pohon penghasil buah konsumsi yang biasanya dimanfaatkan oleh masyarakat sekitar hutan. Jenisjenis pohon penghasil buah konsumsi di Tembawang Dusun Suak belum pernah dilakukan penelitian sebelumnya, sehingga belum ada data dan informasi mengenai jenis-jenis pohon buah konsumsi di kawasan tersebut. Penelitian ini dilakukan untuk mengenal pohon buah konsumsi di Tembawang Dusun Suak. Data dan informasi yang diperoleh dapat dikembangkan bagi pengelolaan Hutan Tembawang Dusun Suak serta masyarakat setempat dapat memanfaatkan baik secara ekonomi maupun sosial.

Tujuan penelitian ini adalah untuk mengidentifikasi dan mendeskripsikan ciri-ciri morfologi jenis-jenis pohon penghasil buah konsumsi pada Kawasan Hutan Tembawang Dusun Suak Desa Manis Raya Kecamatan Sepauk Kabupaten Sintang.

METODE PENELITIAN

Penelitian dilaksanakan di Hutan Tembawang Dusun Suak Desa Manis Raya Kecamatan Sepauk Kabupaten Sintang, mulai dari 22 April sampai 7 Mei 2019. Objek penelitian ialah semua jenis pohon penghasil buah konsumsi di Hutan Tembawang Suak. Alat dan bahan yang digunakan; Peta lokasi penelitian, kamera untuk dokumentasi penelitian, GPS untuk memberi titik koordinat, phiband untuk mengukur diameter pohon, hagameter untuk mengukur tinggi pohon, tally sheet untuk pencatatan data lapangan, toples dan amplop untuk spesimen. Peralatan yang digunakan dalam pengumpulan spesimen yaitu galah, sasak, gunting. Peralatan dalam pembuatan herbarium yaitu, spiritus, koran, plastik packing, karton, cutter, label keterangan, dan etiket gantung. Penelitian ini dilaksanakan dengan menggunakan metode eksplorasi dan koleksi flora, yang dilakukan dengan menjelajahi setiap sudut lokasi penelitian (Rugayah, 2004). Pengambilan data dilakukan dengan membuat jalur-jalur sebanyak 10 jalur, dengan jarak antar jalur 20 meter dan panjang jalur mengikuti sampai 
batas hutan tembawang dengan wilayah hutan lain dengan panjang jalur antara 30-50 meter.

Data yang dikumpulkan dibedakan atas data primer dan data sekunder. Data primer merupakan data yang diperoleh dari identifikasi jenis pohon berupa nama lokal, tinggi pohon, diameter pohon, ciri-ciri morfologi vegetative maupun generative (jika tersedia), nama ilmiah (dapat langsung dicatat jika diketahui), habitat, ketinggian tempat, titik koordinat lokasi, nomor koleksi, tanggal pengamatan, dan contoh koleksi spesimen berupa daun, buah, dan bunga (jika tersedia). Semua jenis pohon tersebut dicatat kedalam tally sheet pengamatan, kemudian dianalisis lebih lanjut dengan melakukan identifikasi jenis pohon. Identifikasi dilakukan dengan menggunakan buku identifikasi, literatur, dan mencocokkan dengan herbarium yang pernah ada. Data identifikasi dimasukkan kedalam tabel daftar jenis pohon yang ditulis menggunakan nama latin sesuai Binomial Nomenclature beserta nama lokalnya dan penulisan dikelompokkan berdasarkan familinya masing-masing.

Data sekunder merupakan data yang dibutuhkan sebagai data penunjang dalam penelitian ini adalah keadaan umum lokasi, curah hujan, geologi dan jenis tanah, aksesibilitas, tipe hutan, serta data lain yang dapat di jadikan penunjang dalam penelitian ini.

Analisis data yang digunakan adalah analisis deskriptif, yaitu dengan cara mendeskripsikan ciri-ciri morfologi (generatif maupun vegetatif) secara detail pada semua jenis pohon penghasil buah konsumsi yang ditemukan di setiap jalur penelitian.

\section{HASIL DAN PEMBAHASAN}

Hasil penelitian identifikasi jenisjenis pohon penghasil buah konsumsi pada Hutan Tembawang Suak, ditemukan 30 jenis pohon buah konsumsi yang tergolong ke dalam 16 genus dan 13 famili. Wulandari (2018), dalam penelitiannya ditemukan 24 jenis dan 13 Famili pohon buah di Hutan Tembawang Desa Empiyang, Kecamatan Jangkang, Kabupaten Sanggau. Berdasarkan status konservasi, 5 jenis tergolong ke dalam status konservasi IUCN redlist, diantaranya 3 jenis tergolong vulnarable (rentan) yaitu Artocarpus anisophyllus Miq. (Mentawak), Durio kutejensis (Hassk.) Becc. (Pekawai) dan Manginfera pajang Kosterm (Asam Mawang), dan 3 jenis tergolong least concern (resiko rendah) yaitu Artocarpus elasticus Reinw. ex Blume. (Terap) Artocarpus sericicarpus F.M Jarrett (Peluntan), Pohon buah konsumsi di Hutan Tembawang Dusun Suak, terdapat 5 jenis yang tergolong dalam status endemik Kalimantan yaitu Manginfera pajang Kosterm (Asam Mawang), Shorea stenoptera Burck. (Tengkawang Tungkul), Durio Kutejensis (Hassk.) Becc. (Pekawai), Sarcotheca macrophylla Blume (Rembai), dan Baccaurea angulata Merr. (Belimbing Darah/Menit). Sebaran pohon peghasil buah konsumsi dapat dilihat pada tabel 1 . 
Tabel 1. Sebaran Masing-Masing Jenis Pohon Penghasil Buah Konsumsi Dalam Jalur Eksplorasi (Distribution of Each Species Consumption Fruit in the Exploration Path)

\begin{tabular}{|c|c|c|c|c|c|c|c|c|c|c|c|}
\hline \multirow[t]{2}{*}{ No. } & \multirow[t]{2}{*}{ Nama jenis Pohon } & \multicolumn{10}{|c|}{ Jalur Eksplorasi } \\
\hline & & 1 & 2 & 3 & 4 & 5 & 6 & 7 & 8 & 9 & 10 \\
\hline 1 & $\begin{array}{l}\text { Aleurites mollucana (L.) } \\
\text { Willd. }\end{array}$ & $\sqrt{ }$ & $\sqrt{ }$ & & & & & & & & \\
\hline 2 & Archidendron jiringa (Jack) & & $\sqrt{ }$ & & $\sqrt{ }$ & $\sqrt{ }$ & $\sqrt{ }$ & $\sqrt{ }$ & & $\sqrt{ }$ & \\
\hline 3 & $\begin{array}{l}\text { Artocarpus anisophyllus } \\
\text { Miq. }\end{array}$ & & & $\sqrt{ }$ & $\sqrt{ }$ & $\sqrt{ }$ & & & & & $\sqrt{ }$ \\
\hline 4 & $\begin{array}{l}\text { Artocarpus elasticus Reinw. } \\
\text { ex Blume }\end{array}$ & & & $\sqrt{ }$ & $\sqrt{ }$ & & & $\sqrt{ }$ & $\sqrt{ }$ & $\sqrt{ }$ & \\
\hline 5 & $\begin{array}{l}\text { Artocarpus heterophyllus } \\
\text { Lam. }\end{array}$ & $\sqrt{ }$ & $\sqrt{ }$ & & & & & & & & \\
\hline 6 & $\begin{array}{l}\text { Artocarpus integer (Thunb.) } \\
\text { Merr }\end{array}$ & & $\sqrt{ }$ & $\sqrt{ }$ & $\sqrt{ }$ & $\sqrt{ }$ & & & $\sqrt{ }$ & & $\sqrt{ }$ \\
\hline 7 & Artocarpus rigidus Blume & $\sqrt{ }$ & & & & $\sqrt{ }$ & $\sqrt{ }$ & & & & \\
\hline 8 & $\begin{array}{l}\text { Artocarpus sericicarpus } \\
\text { F.m.Jarrett }\end{array}$ & & $\sqrt{ }$ & & $\sqrt{ }$ & & $\sqrt{ }$ & $\sqrt{ }$ & $\sqrt{ }$ & & \\
\hline 9 & Baccaurea angulata Merr. & & & & $\sqrt{ }$ & $\sqrt{ }$ & & & $\sqrt{ }$ & $\sqrt{ }$ & \\
\hline 10 & $\begin{array}{l}\text { Baccaurea lanceolata (Miq.) } \\
\text { Mull.Arg. }\end{array}$ & & & $\sqrt{ }$ & & $\sqrt{ }$ & $\sqrt{ }$ & $\sqrt{ }$ & $\sqrt{ }$ & & \\
\hline 11 & $\begin{array}{l}\text { Baccaurea macrocarpa } \\
\text { (Miq.) Mull.Arg. }\end{array}$ & & & $\sqrt{ }$ & $\sqrt{ }$ & & & $\sqrt{ }$ & & $\sqrt{ }$ & \\
\hline 12 & $\begin{array}{l}\text { Baccaurea motleyana } \\
\text { (Mull.Arg.) Mull.Arg. }\end{array}$ & $\sqrt{ }$ & $\sqrt{ }$ & & & & & & & & \\
\hline 13 & Dacryodes rostrata (BI.) & & & $\sqrt{ }$ & $\sqrt{ }$ & & $\sqrt{ }$ & $\sqrt{ }$ & $\sqrt{ }$ & & \\
\hline 14 & Dimocarpus longan Lour. & & $\sqrt{ }$ & & $\sqrt{ }$ & & & & & & $\sqrt{ }$ \\
\hline 15 & $\begin{array}{l}\text { D. longan Subsp. Malesianus } \\
\text { var. malesianus Leenh. }\end{array}$ & $\sqrt{ }$ & $\sqrt{ }$ & & $\sqrt{ }$ & $\sqrt{ }$ & $\sqrt{ }$ & $\sqrt{ }$ & $\sqrt{ }$ & $\sqrt{ }$ & \\
\hline 16 & Durio kutejensis (Hassk.) & & & $\sqrt{ }$ & $\sqrt{ }$ & & $\sqrt{ }$ & & & & \\
\hline 17 & Durio zibethinus Murr. & & $\sqrt{ }$ & $\sqrt{ }$ & & $\sqrt{ }$ & $\sqrt{ }$ & $\sqrt{ }$ & $\sqrt{ }$ & & $\sqrt{ }$ \\
\hline 18 & $\begin{array}{l}\text { Elateriospermum tapos } \\
\text { Blume. }\end{array}$ & & & $\sqrt{ }$ & & & & & $\sqrt{ }$ & $\sqrt{ }$ & $\sqrt{ }$ \\
\hline 19 & $\begin{array}{l}\text { Garcinia parvifolia (Miq.) } \\
\text { Miq. }\end{array}$ & & & $\sqrt{ }$ & & $\sqrt{ }$ & $\sqrt{ }$ & $\sqrt{ }$ & & & \\
\hline 20 & Lansium domesticum Correa & & $\sqrt{ }$ & & $\sqrt{ }$ & & $\sqrt{ }$ & $\sqrt{ }$ & & $\sqrt{ }$ & \\
\hline 21 & $\begin{array}{l}\text { Lepisanthes alata (Blume) } \\
\text { Leenh }\end{array}$ & $\sqrt{ }$ & & & $\sqrt{ }$ & $\sqrt{ }$ & $\sqrt{ }$ & & & & \\
\hline 22 & $\begin{array}{l}\text { Lepisanthes amoena (Hassk.) } \\
\text { Leenh. }\end{array}$ & & & & & & & & & & \\
\hline 23 & Mangifera pajang Kosterm. & & & $\sqrt{ }$ & $\sqrt{ }$ & $\sqrt{ }$ & & & & & \\
\hline 24 & Mangifera $s p$ & & $\sqrt{ }$ & $\sqrt{ }$ & & $\sqrt{ }$ & $\sqrt{ }$ & & & $\sqrt{ }$ & \\
\hline 25 & $\begin{array}{l}\text { Mangifera torquenda } \\
\text { Kosterm. }\end{array}$ & & & & $\sqrt{ }$ & & $\sqrt{ }$ & $\sqrt{ }$ & & & \\
\hline 26 & $\begin{array}{l}\text { Nephelium cuspidatum } \\
\text { Blume }\end{array}$ & & & $\sqrt{ }$ & $\sqrt{ }$ & & & $\sqrt{ }$ & $\sqrt{ }$ & $\sqrt{ }$ & \\
\hline 27 & Nephelium lappaceum L. & $\sqrt{ }$ & $\sqrt{ }$ & & & $\sqrt{ }$ & & $\sqrt{ }$ & $\sqrt{ }$ & & $\sqrt{ }$ \\
\hline 28 & $\begin{array}{l}\text { Sarcotheca macrophylla } \\
\text { Blume }\end{array}$ & & & & $\sqrt{ }$ & & & & & $\sqrt{ }$ & \\
\hline 29 & Shorea stenoptera Burck. & & & $\sqrt{ }$ & & $\sqrt{ }$ & $\sqrt{ }$ & $\sqrt{ }$ & & & \\
\hline 30 & $\begin{array}{l}\text { Sloanea javanica (Miq.) } \\
\text { Szyl. Ex K. Schum }\end{array}$ & & & & & $\sqrt{ }$ & & & & & $\sqrt{ }$ \\
\hline & $\begin{array}{c}\text { Total } \\
\end{array}$ & 7 & 13 & 14 & 17 & 15 & 15 & 14 & 11 & 10 & 7 \\
\hline
\end{tabular}


Berdasarkan tabe1, jumlah jenis pohon buah konsumsi dari masingmasing jalur sangat bervariasi. Jalur eksplorasi dengan jenis terbanyak adalah jalur 4 dengan jumlah 17 jenis pohon penghasil buah konsumsi, famili yang paling banyak pada jalur ini adalah famili moroceae dan sapindaceae ditemukan 4 jenis pohon penghasil buah konsumsi. Jalur 5 dan 6 dengan jumlah yang sama, dengan masing-masing 15 jenis pohon penghasil buah konsumsi, jalur 5, famili yang banyak ditemukan yaitu famili sapindaceae dan moraceae ditemukan 3 jenis pohon penghasil buah konsumsi dari famili tersebut. Jalur 6 famili yang banyak ditemukan adalah famili sapindaceae dengan jumlah jenis pohon penghasil buah konsumsi yang ditemukan ada 3 jenis. Jalur 3 dan 7 dengan jumlah yang sama, dengan masing-masing 14 jenis pohon penghasil buah konsumsi, jalur 2 dengan jumlah 13 jenis pohon, jalur 8 dengan jumlah 11 jenis pohon penghasi buah konsumsi, jalur 9 dengan jumlah 10 jenis pohon penghasil buah konsumsi. Jalur ekplorasi dengan jumlah jenis paling sedikit adalah jalur 1 dan jalur 10 dengan jumlah 7 jenis pohon penghasil buah konsumsi. Jenis-jenis pohon pada jalur 4 , 5 dan 6 memiliki jumlah jenis yang lebih tinggi jika dibandingkan jalur 1 dan 10 . Hal tersebut dikarenakan jalur 4, 5 dan 6 berada di tengah Hutan Tembawang Suak, kondisi vegetasi pada jalur tersebut tergolong masih berhutan, sedangkan pada jalur 1 dan 10 merupakan batas tepi Hutan Tembawang
Suak dengan kondisi vegetasi sangat jarang dan didominasi pohon kecil serta semak belukar.

Jenis pohon penghasil buah konsumsi yang paling dominan dalam setiap jalur adalah Dimocarpus longan Lour. subsp. malesianus var. malesianus Leenh., jenis ini ditemukan pada 8 jalur eksplorasi, diantaranya pada jalur 1, 2, 4, 5, 6, 7, 8, dan 9, jenis Dimocarpus longan Lour. subsp. malesianus var d. malesianus Leenh., sering ditemukan pada jalur-jalur yang diamati, dan mendominasi didalam jalur yang diamati. Durio zibethinus Murr. (Durian) ditemukan pada 7 jalur ekplorasi, kemudian Archidendron jiringa (Jack) Nielsen (Jengkol) dan Artocarpus integer (Thunb.) Merr. (Cempedak) ditemukan pada 6 jalur eksplorasi. Jenis-jenis tersebut sangat umum di tumbuh pada hutan sekunder dataran rendah seperti di Hutan Tembawang Suak. Jenis yang paling jarang ditemukan dalam jalur eksplorasi adalah Aleurites mollucana (L.) Willd. (Kemiri), Artocarpus heterophyllus Lam. (Nangka) dan Baccaurea motleyana (Mull. Arg.) Mull. Arg. (Rambai), Sloanea javanica (Miq.) Szyl. ex. K. Schum (Mercapan), jenis-jenis tersebut hanya ditemukan pada 2 jalur eksplorasi dan Lepianthes amoena (Hassk.) Leenh. (Buah Kijang) yang hanya ditemukan pada satu jalur.

Jenis-jenis pohon penghasil buah yang dapat dikomsumsi berdasarkan familinya dapat dilihat pada tabel 2 . 
Tabel 2. Daftar Jenis Pohon Penghasil Buah Konsumsi yang Ditemukan pada Hutan Tembawang Suak di Kelompokkan Berdasarkan Famili (List of Consumable Fruit Trees Found in Tembawang Suak Forest Grouped by Family)

\begin{tabular}{|c|c|c|c|c|}
\hline No. & Famili & Nama Ilmiah & Nama Indonesia & Nama Lokal \\
\hline 1 & 2 & 3 & 4 & 5 \\
\hline \multirow[t]{3}{*}{1} & Anacardiaceae & Mangifera pajang Kosterm. & Asam Mawang & Mawang \\
\hline & & Mangifera sp & Asam Paoh & Paoh \\
\hline & & Mangifera torquenda Kosterm. & Kemantan & Kemantik \\
\hline 2 & Burseraceae & Dacryodes rostrata (BI.) H.J.Lam. & Kemayau & Kemayau \\
\hline 3 & Clusiaceae & Garcinia parvifolia (Miq.) Miq. & Kandis & Kandis \\
\hline 4 & Dipterocarpaceae & Shorea stenoptera Burck. & Tengkawang & Engkabang \\
\hline 5 & Elaeocarpaceae & Sloanea javanica (Miq.) Szyl. Ex K. Schum & Mercapan & Mercapan \\
\hline \multirow[t]{2}{*}{6} & Euphorbiaceae & Aleurites mollucana (L.) Willd. & Kemiri & Kemiri \\
\hline & & Elateriospermum tapos Blume. & Kelampai & Kelampai \\
\hline 7 & Fabaceae & Archidendron jiringa (Jack) Nielsen. & Jengkol & Jering \\
\hline \multirow[t]{2}{*}{8} & Malvaceae & Durio kutejensis (Hassk.) Becc. & Pekawai & Pekawai \\
\hline & & Durio zibethinus Murr. & Durian & rian \\
\hline 9 & Meliaceae & Lansium domesticum Correa & Langsat & Lensat \\
\hline \multirow[t]{6}{*}{10} & Moraceae & Artocarpus anisophyllus Miq. & Mentawak & Mentawak \\
\hline & & Artocarpus elasticus Reinw. ex Blume & Terap & Kepuak \\
\hline & & Artocarpus heterophyllus Lam. & Nangka & Nangkak \\
\hline & & Artocarpus intger (Thunb.) Merr. & Cempedak & Tebedak \\
\hline & & Artocarpus rigidus Blume & Pintau & Pintau \\
\hline & & Artocarpus sericicarpus F.M.Jarrett & Peluntan & Peluntan \\
\hline 11 & Oxalidaceae & Sarcotheca macrophylla Blume & belimbing hutan & Rembai \\
\hline \multirow[t]{4}{*}{12} & Phyllanthaceae & Baccaurea angulata Merr. & Belimbing Darah & Menit \\
\hline & & Baccaurea lanceolata (Miq.) Mull.Arg. & Lempaung & Lempaung \\
\hline & & Baccaurea macrocarpa (Miq.) Mull.Arg. & Tampoi & Mak \\
\hline & & Baccaurea motleyana (Mull.Arg.) Mull.Arg. & Rambai & Rambai \\
\hline \multirow[t]{6}{*}{13} & Sapindaceae & Dimocarpus longan Lour. & Kelengkeng & Belengkiang \\
\hline & & $\begin{array}{l}\text { Dimocarpus longan Lour. Subsp. malesianus var. } \\
\text { malesianus Leenh. }\end{array}$ & Kelengkeng & Lengkuis \\
\hline & & Lepisanthes alata (Blume) Leenh. & Kerantik & Kerantik \\
\hline & & Lepisanthes amoena (Hassk.) Leenh. & Buah Kijang & Buah Kijang \\
\hline & & Nephelium cuspidatum Blume & Rambutan & Sibau \\
\hline & & Nephelium lappaceum L. & Rambutan & Belikik \\
\hline
\end{tabular}

Berdasarkan tabel 2, diketahui terdapat 13 famili yang ditemukan pada Hutan Tembawang yaitu; Anacardiaceae, Burseraceae, Clusiaceae, Dipterocarpaceae, Elaeocarpaceae, Euphorbiaceae, Fabaceae, Malvaceae, Meliaceae, Moraceae Oxalidaceae, Phyllanthaceae, Sapindaceae. Jenis famili yang paling dominan ialah famili Moraceae dan famili Sapindaceae ini dikarenakan ada 6 jenis pohon penghasil buah konsumsi yang ditemukan pada lokasi penelitian dari famili keduanya, pada setiap jalur penelitian jenis dari famili Moraceae dan Sapindaceae sering dijumpai. Famili kedua yang banyak ditemukan jenis pohon buah konsumsi ialah famili Phyllanthaceae ada 4 jenis pohon buah konsumsi yang ditemukan pada lokasi penelitian. Famili Anacardiaceae ditemukan ada 3 jenis pohon buah konsumsi, famili Euphorbiaceae dan famili Malvaceae ada 2 jenis pohon penghasil buah konsumsi yang ditemuakan pada kedua famili tersebut. Famili Burseraceae, 
Clusiaceae,

Dipterocarpaceae,

Elaeocarpaceae, Fabaceae, Meliaceae, dan famili Oxalidaceae dari famili-famili ini hanya ditemukan 1 jenis pohon penghasil buah konsumsi untuk setiap familinya pada lokasi penelitian.

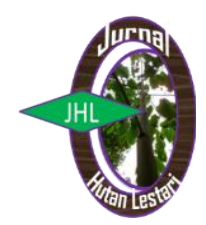

Berdasarkan penelitian ditemukan 30 jenis pohon penghasil buah konsumsi pada lokasi penelitian, terdapat 5 jenis yang memiliki status endemik Kalimantan, dari jenis pohon buah tersebut dapat dilihat pada tabel 3 .

Tabel 3. Daftar Jenis Pohon Penghasil Buah Konsumsi yang Tergolong ke dalam Status Endemik Kalimantan (List Of Species Trees Fruit Consumption That are Classified as Kalimantan Endemic)

\begin{tabular}{|c|c|c|}
\hline No & Nama Ilmiah & Keterangan \\
\hline 1. & $\begin{array}{l}\text { Manginfera pajang } \\
\text { Kosterm }\end{array}$ & $\begin{array}{l}\text { Memiliki nama lokal asam mawang, berupa pohon besar dengan tinggi mencapai } 20-30 \text { meter, } \\
\text { berdiameter mencapai } 60 \mathrm{~cm} \text {, batang pohon berbentuk silindris, permukaan batang beralur, pangkal } \\
\text { batang diatas permukaan tanah, tidak berbanir, getah berwarna coklat kemerahan lengket. Daun } \\
\text { tunggal, bentuk daun oblong, ada stipule, buah bulat, kasar, warna coklat muda buah berdiameter } \\
\text { mencapai } 10-12 \mathrm{~cm} \text {, daging buah berwarna kuning, berserat panjang, rasa asam manis, buah dapat } \\
\text { dikonsumsi langsung. }\end{array}$ \\
\hline 3. & $\begin{array}{l}\text { Durio kutejensis } \\
\text { (Hassk.) Becc }\end{array}$ & $\begin{array}{l}\text { Memiliki nama lokal pekawai berupa pohon berukuran besar dengan tinggi mencapai } 20 \text { meter, } \\
\text { diameter mencapai } 35 \mathrm{~cm} \text {, batang pohon berbentuk silindris, berbanir, warna kulit batang abu } \\
\text { kecoklatan dengan permukaan kulit batang kasar. Daun tunggal berbentuk bulat telur terbalik, } \\
\text { permukaan bawah daun berwarna keemasan, permukaan atas berwarna hijau, ada pembengkakan } \\
\text { pada tangkai daun, terdapat stipule. Buah bulat berduri dengan ujung duri berwarna kecoklatan } \\
\text { panjang duri } 1 \mathrm{~cm} \text {, buah berdiameter } 18 \mathrm{~cm} \text {, daging buah berwarna kuning-orange, rasa buah manis } \\
\text { jika sudah masak. }\end{array}$ \\
\hline 4. & $\begin{array}{l}\text { Sarcotheca macrophylla } \\
\text { Blume }\end{array}$ & $\begin{array}{l}\text { Memiliki nama lokal rembai berupa pohon kecil, dengan tinggi mencapai } 12 \text { meter dan diameter } \\
\text { mencapai } 10 \mathrm{~cm} \text {, batang pohon silindris tidak berbanir, kulit batang tidak bergetah. Daun majemuk, } \\
\text { tipis, berbentuk lonjong terdapat pembengkakan pada ujung dan pangkal tangkai daun, daun } \\
\text { berwarna hijau tua mengkilap. Buah majemuk berwarna merah gelap, buah muncul pada ujung } \\
\text { percabangan rasa buah asam dapat dikonsumsi langsung. }\end{array}$ \\
\hline 5. & $\begin{array}{l}\text { Baccaurea angulata } \\
\text { Merr. }\end{array}$ & $\begin{array}{l}\text { Memiliki nama lokal belimbing darah berupa pohon dengan tinggi mencapai } 20 \text { meter dan } \\
\text { berdiameter mencapai } 40 \mathrm{~cm} \text {,batang berbentuk silindris, tidak memiliki banir, daun tunggal, tebal } \\
\text { dan licin, daun berbentuk ellips hingga bulat telur terbalik, daun berwarna hijau tua mengkilap, ada } \\
\text { pembengkakan pada ujung dan pangkal daun. Buah majemuk menumpuk, terletak pada batang } \\
\text { buah berbentuk buah telur terbalik, berwarna merah muda hingga merah tua, rasa buah manis dan } \\
\text { kadang asam dapat dikonsumsi langsung. }\end{array}$ \\
\hline
\end{tabular}

Berdasarkan tabel 3 diatas, dari ke 5 jenis pohon penghasil buah konsumsi tergolong kedalam famili Anacardiaceae (Mangifera pajang Kosterm), famili Malvaceae (Durio kutejensis (Hassk.) Becc.), famili Oxalidaceae (Sarcotheca macrophylla Blume), famili Phyllantaceae (Baccaurea angulata Merr.) dan famili Dipterocarpaceae (Shorea stenoptera Burck.).

\section{KESIMPULAN}

Berdasarkan hasil penelitian ditemukan 30 jenis pohon buah konsumsi yang tergolong dalam 16 genus dan 13 famili. Sebanyak 5 jenis yang tergolong dalam status endemik Kalimantan yaitu Manginfera pajang Kosterm (Asam Mawang), Shorea stenoptera Burck. (Tengkawang Tungkul), Durio Kutejensis (Hassk.) Becc. (Pekawai), Sarcotheca 
macrophylla Blume (Rembai), Baccaurea angulata Merr. (Belimbing Darah/Menit). Famili dengan jumlah pohon buah konsumsi terbanyak ditemukan pada setiap jalur yaitu famili Moraceae dan Sapindaceae. Jenis pohon yang paling dominan dalam setiap jalur adalah Dimocarpus longan Lour. subsp. malesianus var. malesianus Leenh.

\section{UCAPAN TERIMA KASIH}

Penulis mengucapkan terimakasih kepada Bapak Tanu, selaku tetua adat lama yang mengelola dan memperhatikan Hutan Tembawang Dusun Suak, Desa Manis Raya, yang membantu penulis dalam pengambilan data di lapangan.

\section{DAFTAR PUSTAKA}

Darusman, D. 2001. Resilinsi Kehutanan Masyarakat Di Indonesia. Yogyakarta. Debut Press.

Hani A. 2009. Pengembangan Tanaman Penghasil Hasil Hutan Bukan Kayu Melalui Perbanyakan Vegetatif. Balai Penelitian Kehutanan, Ciamis.
Roslinda E \& Yuliantini. 2006. Valuasi Ekonomi Jasa Lingkungan Daerah Alir Sungai Taman Nasional Betung Kerihun (Sub DAS Mendalam, Sibau dan Kapuas). Kabupaten Kapuas Hulu Kalimantan Barat.

Rugayah. Retnowati A, Windradi FI, Hidayat. 2004. Pedoman Pengumpulan Data Keanekaragaman Flora. Bogor: Pusat Penelitian Biologi LIPI.

Wahyuni S, Manurung TF, Kartikawati SM. 2017. Identifikasi Pohon Penghasil Buah pada Kawasan Hutan Lindung Gunung PemancingGunung Ambawang Bukit Bendera Kecamatan Teluk Pakedai Kabupaten Kubu Raya. Jurnal Hutan Lestari 5(2) : 225-233.

Mutiara W, Manurung TF. 2018. Identifikasi Pohon Penghasil Buah yang Dimanfaatkan Masyarakat Di Hutan Tembawang. Jurnal Hutan Lestari 6(3) : 697-707. 